\title{
'n Historiese oorsig met kommentaar oor 'Kritiese Skrifbeskouing'
}

M. A. Kruger

\section{INLEIDENDE OPMERKINGS}

1.1 Die doel van hierdie voordrag

Die doel van hierdie voordrag is om 'n historiese agtergrond te bied van "kritiese Skrifbeskouings" soos dit vanuit gereformeerde standpunt en tradisie gesien kan word. Vervolgens is die mikpunt ook om die eie standpunt in verhouding tot hierdie beeld te kan sien aangesien dit dikwels net teenoor los aspekte van die historiese beeld opgeweeg word.

\subsection{Wat word bedoel met "krities"?}

Met "krities" word in die opskrif nie bedoel bloot beoordeel, oorweeg, beskou nie. Dit word in negatiewe sin gebruik, naamlik waar die norm vir Skrifverklaring ontleen word aan 'n ander bron as aan die Skrif self, byvoorbeeld die verstand, en dit dan in stryd is met die eie aard van die Skrif (vgl. 0.a. Fryer, 1987:44, 45).

\subsection{Wat word bedoel met "Skrif"?}

Met "Skrif" word bedoel die kanonieke boeke van die Ou Testament en die Nuwe Testament wat volgens die belydenis van die gereformeerde kerke as Woord van God aanvaar word. Wanneer, vanuit hierdie belydenisstandpunt gesien, die omvang van die Skrif anders gesien word, tree onmiddellik al die negatief kritiese element na vore.

\subsection{Wat is 'n "kritiese Skrifbeskouing"?}

Feenstra (1961:117) het die volgende omskrywing gegee van 'n kritiese Skrifbeskouing: "Onder Schriftkritiek verstaan wij een benadering van de Heilige Schrift, waarbij zij niet, of althans niet in haar geheel, wordt aanvaard als het betrouwbare Woord van God, maar waarbij, op zijn minst voor bepaalde gedeelten, die betrouwbaarheid wordt ontkend." Hierdie definisie is nie meer bruikbaar nie. Die probleem lê in die woord "betrouwh rarheid". Is Genesis 1 - 3 byvoorbeeld, betroubare Woord van God as dit nie histories verstaan word nie, of as dit wel histories verstaan word? 'n Kritiese Skrifbeskouing is een wat die aard en die gesag van die Skrif anders sien as wat dit vanuit die Skrif self gesien behoort te word. In hierdie sin kan dus ook die sogenaamde gereformeerde Skrifbeskouings krities wees.

\subsection{Die regte Skrifbeskouing?}

Sodra 'n mens vanuit die naiewe spraakgebruik na 'n meer teologiesverantwoorde omlyning van 'n Skrifbeskouing beweeg, waar dogmatiese terme nie aksiomaties aanvaar word as bewysmateriaal nie, kom die besef gou dat die gangbare gereformeerde Skrifbeskouing vol ernstige probleme is. Die laaste woord is nie gesê met die gebruik van dogmatiese terme soos kanon en inspirasie nie. 


\subsection{Metodologiese opset}

Die oorsig wat hier gegee word, val uiteen in twee dele, wat 'n metodologiese (maar nie 'n prinsipiële) verdeling bied. Die eerste deel handel oor die omvang van die lys boeke wat as kanoniek aanvaar word en die tweede oor die kritiek op boeke wat volgens gereformeerde belydenis as Skrif aanvaar word. Die onderskeid is dus enigsins tussen omvang en inhoud.

\section{KRITIEK OP DIE OMVANG VAN DIE SKRIF}

\section{1 "Afsluiting van die kanon"}

Algemeen word aanvaar dat die Tora en die Profete as 'n vaste groep Hebreeuse geskrifte teen ongeveer die helfte van die derde eeu voor Christus 'n afgeronde "Skrif" was. Aalders (1952:44) sluit selfs die Geskrifte hierby in. Stuhlmacher (1979:35 - 36, vgl Van Aarde, 1987: 16) meen dat die Ou Testanent eers naby 100 n.C. tot "Skrif" afgerond is. Daar was egter nooit erige formele kerklike besluit wat bepaal het dat sekere boeke van die ou bedeling as kanoniek en ander nie kanoniek aanvaar moet word nie (Koole. 1955:10).

Wat die Nuwe Testament betref, het die besluit van die Sinode van Kartago (397) 'n hepaalde afsluiting gebring ten opsigte van die boeke wat toe algemeen deur die kerk as kanoniek aanvaar is.

Elkeen wat sy geloof bely soos in artikels 4 en 5 van die Nederlandse Geloofsbelydenis, moet uit die aard van die saak 'n afgeslote lys boeke as kanoniek aanvaar. In artikel 5 bely ons van die boeke wat in artikel 4 genoem word: "Ons aanvaar al hierdie boeke, en hulle alleen, as heilig en kanoniek om ons geloof daarna te rig, daarop te grondves en daarmee te bevestig."

Hierdie belydenis moet egter teen die werklikheid van die geskiedenis gesien word. Dwarsdeur die bestaan van die Skrif is deur gelowiges en deur groepe vraagtekens geplaas oor hierdie afgeslotenheid. Ridderbos (1955:82) praat van die "absoluutheid" en die "relativiteit" wat nie van mekaar losgemaak kan word nie: "Want de absoluutheid van de canon is van de relativiteit der geschiedenis niet los te maken." Die belydenis stel absolute grense en verbind hierdie grense aan die leiding van die Heilige Gees wat ons so leer. Die geskiedenis toon dat die omvang van die kanonieke lys altyd relatief gestel is.

\subsection{Beperking op die lys van kanonieke boeke}

In die tyd van Jesus se omwandeling op aarde was daar allermins eenstemmigheid oor wat die Skrif is. Die Sadduseërs het slegs die Tora erken. Die strikvrae wat hulle aan Jesus gestel het hou waarskynlik verband met die beperkte kanonlys wat hulle gehad het. Jesus verwys sydelings hierna as Hy sê dat hulle dwaal omdat hulle die Skrifte nie ken nie. Tog beantwoord Hy hulle vraag vanuit die boeke wat die Sadduseers aanvaar. Ook die Samaritane het slegs die Pentateug aanvaar. Die Tannaiete van na 70 n.C. het prakties op die Wet gekonsentreer, hoewel hulle nie die Profete en die Geskrifte misken het nie (Sanders. 1981':76).

Marcion het teen ongeveer die helfte van die tweede eeu reeds sy eie lys van kanonieke boeke opgestel. Dit het slegs 'n "gesuiwerde" 
Evangelie volgens Lukas en tien van die briewe van Paulus bevat. Sy kanonlys het ongetwyfeld daartoe bygedra dat die kerk besin het oor watter boeke wel as kanoniek beskou moes word. Dié proses van besinning kom in 397 voorlopig met die besluit van Kartago tot afsluiting. Voor 397 is veral oor Hebreërs, Openbaring en 2 Petrus op verskillende plekke verskillend geoordeel (vgl. Stuhlmacher, 1979:36 - 37).

Vanaf 397 is die kanonieke boeke soos ons dit in die Nuwe Testament het, deur die hoofstroom van die kerk aanvaar sover daar besinning daaroor was. Die Roomse struktuur het egter besinning beperk.

Met die Reformasie breek egter 'n nuwe tyd van beoordeling aan. Luther het met sy beoordelingsbeginsel "was Christum treibt" weer bedenkinge gehad oor sommige boeke. Toe Roomse teoloe aan hom Jakobus $2: 24$ voorhou teen sy standpunt van "deur die geloof alleen", het hy besluit dat Jakobus nie met die Evangelie ooreenstem nie. Hy het met sy besinning in dieselfde posisie te staan gekom as waarin die kerk voor 397 was, toe sommige boeke as antilegomena beskou is (Berkouwer, 1966:121 - 124). Dis belangrik om te onthou dat Luther hom nie sodanig aan die kerklike besluit van 397 gebonde geag het dat hy homself nie vry beskou het om te oordeel nie.

Daar is ooreenkoms sowel as verskil tussen Calvyn en Luther. Die ooreenkoms lê daarin dat ook Calvyn homself nie so aan die besluit van 397 gebonde geag het dat hy nie ook geroepe gevoel het om self uit te maak wat kanoniek is nie. Soos Luther veral met "was Christum treibt" geoordeel het, het Calvyn die beginsels van apostolisiteit en waarheid gebruik. Dit blyk uit sy inleidings op sy kommentare oor verskeie boeke. In sy inleiding op Jakobus verwys hy bedek na Luther en besluit dat daar niks in Jakobus is wat bots met die beginsels van apostolisiteit en waarheid nie. Die belangrike verskil tussen Calvyn en Luther is dat eersgenoemde meer gewig toeken aan die besinningsgeskiedenis van die kerk voor 397 as Luther.

Sowel Luther as Calvyn het egter vry gevoel om self te beoordeel wat kanoniek is en wat nie. Calvyn sou beslis as hy dit nodig gevind het, verskil het van die kanonlys van 397 .

\subsection{Uitbreiding op die lys van kanonieke boeke}

Die apokriewe van die ou bedeling het via die Septuaginta eenvoudig op gelyke voet tussen die boeke van die Ou Testament gekom tot op die Reformasie. Dit het gebeur ondanks die protes van mense soos Hieronimus (Aalders, 1956:257). Deur die Hervormers is hulle egter verwerp. Hieruit blyk weer dat die Hervormers hulle nie gebonde geag het aan wat tevore aanvaar is nie. (Dis verbasend dat die kerk wat in die vierde eeu so begaan was oor die kanonieke boeke van die Nuwe Testament so weinig bekommerd was oor die Ou Testament.) Die Rooms-Katolieke Kerk handhaaf nog altyd hierdie apokriewe, met uitsondering van 3 Makkabeërs, hoewel Roomse teoloe gewoonlik praat van apokriewe as deutero-kanonieke boeke.

Voor 397 is in verskillende gebiede ook sekere boeke as kanoniek aanvaar terwyl hulle in ander gebiede verwerp is. Dit geld byvoorbeeld van Die Eerste Brief van Clemens Romanus, Die Leer van die Twaalf Apostels, Die Herder van Hermas en die Brief van Barnabas (Thiessen, 1943:6 - 7) 
In die Bybel is daar self getuienis dat boeke of geskrifte as "Skrif" aanvaar is wat ons as apokrief beskou of wat heeltemal verlore is, soos blyk uit 1 Kor 2 : 9 en Jak 4 : 5 (Stuhlmacher. 1979:36).

\subsection{Wat is die kanon?}

Die diskussie oor wat kanon is en wat nie, het nie na die Reformasie tot 'n einde gekom nie. Karl Barth het byvoorbeeld 'n ander kanon-opvatting gehad. In die jongste tyd is die diskussie tussen Childs en Barr weer afgestem op die kanon-opvatting. Childs wil met gebruikmaking van die Histories-kritiese Metode aan die kanonieke boeke 'n deurslaggewende rol toeken in sy Canonical Criticism. Barr aanvaar nie die uniekheid van die Bybelse boeke in dieselfde mate nie. Hoewel hy ook die Bybel baie hoog ag, verwerp hy die gedagte dat ons hierin openbaring van God het wat die Bybel anders maak as ander middele. Daarom kan dit nie alleen as die deurslaggewende beginsel vir die teologie aanvaar word nie. Vir hom is die kanon wyer as die Bybel. Met die Historieskritiese Metode wil hy dus alle bronne, ook buite die Bybel, gelykelik in aanmerking neem (vgl. Barr, 1983:130 - 171; Childs, 1985:6 - 15 en 20 - 23).

Loader gaan kennelik van die gedagte uit dat die kanon eintlik die waarheid is en dat daarom nie van die kanonieke boeke as dié kanon gepraat kan word nie. Die waarheid is immers wyer as die kanonieke boeke.

Daarom het hy by geleentheid ' $n$ openingsrede by die teologiese fakulteit van Unisa gehou oor 'n uitspraak van Jesus Sirach (1984:2 - 4).

Die voortdurende gesprek oor 'n kanon in die kanon, én die onbewuspraktiese hantering van die Bybel asof daar ' $n$ kanon in die kanon is, toon ook dat daar by 'n groot deel van die kerk nie 'n dogmatiese of aksiomatiese aanvaarding van die Bybel as dié kanon is nie. (Per slot van rekening is slegs Jesus Christus die kanon.)

\section{KRITIEK OP DIE INHOUD VAN DIE SKRIF}

\subsection{Die norm waarteenoor die geskiedenis gestel word}

Afgesien van die belydenisstandpunt is dit nodig om 'n nadere omskrywing te gee van die norm waarteenoor die geskiedenis gestel word. In die na-reformatoriese tyd het daar 'n sterk, maar nie deeglik verantwoorde, dogmatiese grondslag ontstaan in die gereformeerde Skrifbeskouing. Daarom kan die Skrifbeskouing van Calvyn beter dien as maatstaf. Dit het die volgende belangrike kenmerke bevat (vgl. ook Van Wyk, 1987:4-8):

1. Calvyn het die Skrif as openbaring van God aanvaar.

2. Die Skrif bring Christus en nie dogmas nie.

3. Hoewel die Heilige Gees ook sonder die Skrif lei en selfs tot geloof bring, word die kerk gelei deur die Gees met die Woord (Inst. IV 8:11, 13; vgl. IV 1:6 en IV 16:19).

4. Calvyn het geen uitgewerkte inspirasieleer gehad nie.

5. Die gesag van die Skrif is nie 'n objekticwe werklikheid nie, maar bestaan alleen vir diegene wie se harte deur die Heilige Gees vernuwe is. Die Skrif kan dus nie verstaan word deur ongelowiges nie.

6. Calvyn het vrymoediglik tekskritiek beoefen, maar in verband met historiese "foute" 'n versigtige apologetiese standpunt gehandhaaf. 
Ondanks na-reformatoriese veranderings het die gereformeerde beskouing redelik naby hieraan gebly.

\subsection{Die wortels van Skrifkritiek}

Die wortels van die Skrifkritiek is te vinde in 'n beweging wat reeds gelyktydig met die Reformasie bestaan het (Reventlow. 1985:3). Uit 'n laatmiddeleeuse Spiritualisme, Rasionalisme wat reeds gedurende die Reformasie aan die werk was, moralistiese tendense van die Humanisme, en met bykomende invloede van die Anabaptisme, het die latere twee groot kragte in Engeland ontstaan wat uitgeloop het op Puritanisme en rasionalistiese Liberalisme. Uit die rasionalistiese Liberalisme het die Latitudinarianisme ('n rigting wat gepleit het vir ruimte in die godsdiens en hulle verset het teen die Engelse staatskerk) gespruit. Erasmus van Rotterdam het as voorloper van die rigting reeds tydens die Reformasie gepleit vir onderskeid tussen adiaphora en fundamentele sake (Reventlow, 1985:48; Kummel, 1978':51).

\subsection{Die Engelse Deisme}

Die begin van die historiese kritiek moet nie in Duitsland gesoek word nie, maar in Engeland (Barr in Reventlow 1985 : xii). Die Latitudinarianisme was 'n voorloper van die Deisme.

Herbert van Cherbury (1582-1648) was die grondlegger van die Deisme. Hy het vyf stellings gemaak oor ware godsdiens: God bestaan. Hy moet aanbid word. Deug is die hoofsaak van aanbidding. Daar moet berou oor sondes wees. Daar is beloning en straf na hierdie lewe. Hierdie reduksie-godsdiens maak hom vader van die Deiste (Logan. 1987:132). Sy ontwikkelde Skrifkritiese program is kenmerkend van die latere Verligting (Reventlow, 1985:193).

Locke (1632 - 1704) het met sy "Reasonableness of Christianity, as delivered in the Scriptures" sy oortuiging gestel dat die Skrif niks meer vereis ten opsigte van Jesus as om te glo dat Hy opgestaan het en dat Hy Messias is nie. Hiermee was hy in lyn met die algemene rigting van die Deisme wat oorlog verklaar het teen alles wat bonatuurlik is, hoewel hy tog nog aan die opstanding vashou (Kummel, 1978²:51, 52).

Toland (1670 - 1722) het voortgebou op die gedagtes van Locke en in sy werk "Christianity not Mysterious" het hy openbaring geheel en al beperk tot rasionele waarhede (Kummel, 1978':54). Twee-en-twintig jaar later lewer hy in "Nazarenus or Jewish, Gentile and Mahometan Christianity" kritiek op die Bybel, die geskiedenis van die oer-Christendom en die ontstaan van die Skrif. Volgens hom is die wese van die Christendom identies aan die algemene moraal en religie (Terlaak Poot. 1961:392).

Tindal $(1660$ - 1733) het in 1730 die boek wat bekend geraak het as die Bybel van die Deiste gepubliseer: "Christianity as old as creation: or the Gospel a republication of the religion of nature" (Kummel, 1978':54). Die Christelike godsdiens was vir hom slegs 'n nuwe vorm van natuurlike godsdiens. Hy betoog dat tussen waarheid en fiksie in die Bybel onderskei moet word. Vanaf sy konklusie dat die apostels ' $n$ fout gemaak het ten opsigte van die tyd van die wederkoms, konkludeer hy dat daar ook ander foute in die Bybel is (Kummel, 1978: 54 ). 


\subsection{Vroeë Duitse kritici}

Reimarus (1694 - 1768) het 'n sewetal geskrifte geskryf op voetspoor van die Engelse Deiste om sy gewete te stil. Later is hulle deur Lessing gepubliseer. Volgens hom moet in die Bybel onderskei word tussen wat die apostels van Jesus vertel het en wat werklikheid was - die probleem van gemeente-teologie! Reimarus sê dat Jesus volledig Jood was wat 'n aardse messiaanse ryk verwag het. Toe dit nie realiseer nie, kom die apostels met die gedagte van 'n lydende verlosser vir die hele mensheid. Ter wille van hierdie teorie steel hulle die liggaam van Jesus uit die graf en verkondig die opstanding (Kummel, 1978:90).

Lessing (1729 - 1781) word die grondlegger van die Twee Bronne Hipotese vir die ontstaan van die Sinoptiese Evangelies (Kummel, 1978':76).

Semler $(1725 \cdot 1791)$ beweer dat die Woord van God en die Heilige Skrif nie identies is nie en dat elke Christen self kan besluit water boeke kanoniek is. Sy eerste stelling bedoel dat historiese boeke nou geen waarde meer het nie. Al die boeke is dus nie geinspireer nie en hulle het nie almal gesag nie (Kummel, 1978:63).

Michaelis (1717-1791) hou daaraan vas dat die kanonieke boeke van apostoliese oorsprong moet wees en verwerp daarom Markus, Lukas en Handelinge (Kummel, 1978':69).

\subsection{Ander Europese Skrifkritici}

Richard Simon (1638 - 1712), 'n Roomse priester, skryf kritiese studies oor die Ou Testament en die Nuwe Testament met die doel om te bewys dat die Protestante hulle nie op die Skrif kan beroep nie (Kummel. $1978^{2}: 40$ - 47).

Jean Astruc (1684 - 1766) het die vader van die Pentateugkritiek en die teorie van Bronnesplitsing geword (Aalders, 1956a:359).

Turetinni (1671 - 1737) verklaar dat die Bybel net soos enige ander boek met die verstand as enigste norm verklaar moet word (Kummel, 1978: $58-60)$.

\subsection{Die Verligting}

Die kenmerke van die Verligting was die verwerping van die tradisionele binding aan die gesag van die Skrif, die handhawing van die verstand as die finale maatstaf en daarmee saam die verwerping van die bonatuurlike. Duitse teoloe neem die leiding in die Verligting.

Bruno Bauer (1809 - 1882) aanhanger van Hegel, word 'n radikale bestryder van die Ortodoksie. Die Evangelies bied nie gemeenteteologie nie, maar is die produkte wat kom vanaf een oorspronklike skrywer. Hulle kom ooreen met 'n historiese roman (Van Unnik, 1956:485 - 486).

$J$. G. Eichhorn (1752 - 1827) bou voort op die werk van Lessing in verband met die oorsprong van die Sinoptiese Evangelies.

D.F. Strauss (1808 - 1874) onderskei op voetspoor van Hegel tussen vorm en idee in die Evangelies. In sy "Das Leben Jesu, kritisch bearbeitet" stel hy die mitiese verklaring in die plek van die tradisionele en rasionalistiese verklarings. Deur filosofiese konstruksies "herstel" hy dan die eintlike Skrifwaarhede (Kummel, 1978':120 - 121). Hy moet beskou word as een van die grondleggers van die Duitse teologie van ons eeu. Sy invloed 
op Bultmann is duidelik. Filosowe begin nou ' $n$ al groter rol speel in die rigting-bepaling van teologie.

F. C. Baur $(1792-1860)$ erken aanvanklik nog die bonatuurlike, maar stel later alle godsdienste op gelyke vlak. Ten opsigte van Handelinge onderskei hy 'n Joodse party en 'n Hellenistiese party. Hy soek na die bronne wat ten grondslag lé van die Nuwe Testament en word so die vader van Vormkritiek. Paulus is volgens hom nie die skrywer van die Pastorale briewe nie (Kummel, 1978':127, 128).

William Wrede (1859-1906) met sy "Das Messiasgeheimnis in den Evangelien" sê dat die beeld van Jesus wat in die Evangelies weerspieel word die geloof van die vroee kerk uitbeeld en dat die werklike Jesusbeeld slegs dofweg hieruit herkenbaar is (Kummel, 1978':284, 285). Bousset (1865-1920), grondlegger van die Godsdiens-historiese Skool, meen dat die Christelike godsdiens die produk is van elemente uit verskillende ander godsdienste (Kummel, 1978:230, 251. 259. 260).

Troeltsch (1865 - 1923) was die groot sistematikus van teologiese liberalisme en historisisme. Verskillende dele van die Histories-kritiese Metode was nou reeds in gebruik. Hy stel dat historiese kritiek werk met drie onlosmaaklike beginsels: sistematiese skeptisisme, analogie en korrelasie (Stuhlmacher, 1977:44, 45).

\subsection{Vanaf Die Verligting tot vandag}

3.7.1 Metode-diktatuur. Die huidige tyd word gekenmerk deur 'n metodediktatuur by 'n groot persentasie van die voorstanders van die Historieskritiese Metode. Ondanks Barr (1983:130, 131) se ontkenning dat dit die geval is, moet ons aanvaar dat dit wel so is. Daarvoor is die getuienis sterk, ook vanuit die kring van diegene wat aanhangers van die Histories-kritiese Metode is of was en diegene wat 'n goeie kennis daarvan het.

Eta Linneman (s.j. :3.4) weier om haar kritiek te sien as kritiek op die Histories-kritiese Metode. Sy hou vol dat die metode die teologie in so 'n mate oorheers dat gepraat moet word van Histories-kritiese Teologie.

Hans-Herbert Stoldt het skerp kritiek gelewer op die argumente waarmee die Histories-kritiese Metode die Markus-hipotese onderskryf ( 1977). William R. Farmer het by die Engelse vertaling van Stoldt se werk 'n aanprysende woord geskryf nadat sy aandag deur Bo Reicke gevestig is op Stoldt (1980). Farmer openbaar ook die onbillike kritiek van Conzelmann teen Stoldt (1980: xiv - xvii). Childs se diskussie met Barr gaan ook oor die oordrywing van die Histories-kritiese Metode (vgl p . 6). Childs wys nie die verskillende komponente van diê metode af nie. Hy wil hulle egter gebruik sonder om beoordelingsmaatstawwe vir die Skrif buite of agter die Skrif te vind en met inagneming van die aard en totstandkoming van die Skrif in die geloofsgemeenskap (1985:6). Maier (1978') meen dat die Histories-kritiese Metode vol is van innerlike kontradiksies en dat daar nie sin in is om dit verder te gebruik nie. Stuhlmacher meen dat Maier te negatief is. Sanders $\left(197^{\prime}: 15\right)$ vermeld die onbetroubaarheid van Vormkritiese resultate. Harrisville sê in 'n inleiding op Stuhlmacher se "Historical Criticism and Theological Interpretation of Scripture" die volgende: " . . . we should encounter in Peter Stuhlmacher a scholar who sounds alarm respecting the autonomy, independence, and the 
standoffishness assumed by the historical critic" (Stuhlmacher. 1977:7; vgl 1979:22-32).

\subsection{2 'n Hermeneutiek van Instemming teenoor Metode-diktatuur}

Stuhlmacher het in sy boek "Schriftauslegung - auf der Wege zur biblischen Theologie" (1975) 'n afdeling "Historische Kritik und theologische Schriftauslegung". Hier wys hy die leemtes van die gebruik van die Histories-kritiese Metode duidelik uit en dui myns insiens die regte weg aan. Hy stel hom in genoemde hoofstuk ten doel om die moontlikhede en beperkinge van die metode te omlyn (1975:61). Teenoor die diktatuur van die Histories-kritiese Metode stel hy sy Skrifbenadering as 'n Hermeneutiek van Instemming met die Tekste van die Skrif. Een van die belangrikste aspekte van hierdie benadering is juis 'n openheid vir transendensie (1975:125. 126). Die Verligting en die Histories-kritiese Metode het juis hiervoor geen oog nie. Stuhlmacher se konklusie is baie belangrik: "Historischkritische Exegese ist nicht schon in sich und als solche theologische Schriftauslegung. Sie kan aber dazu werden, wenn sie hermeneutisch als Interpretation des Einverständnisses mit den biblischen Texten reflektiert und theologisch in Ansehung der bleibenden hermeneutischen Relevanz des 3. Glaubensartikels in Apostolicum betrieben wird" (1975:126).

Dit bring ons by die belangrike plek van die leiding van die Heilige Gees by alle Skrifverklaring. Terwyl daar in die diskussie rondom die Skrifbeskouing heelwat aandag gegee word aan die plek van die Heilige Gees by die totstandkoming van die Skrif, en dus aan $2 \operatorname{Tim} 3: 16$, word byna geen aandag gegee aan die rol van die Gees by die uitleg van die Skrif en aan 2 Pet 1 : 20 nie. Dis opmerklik dat iemand soos James Barr feitlik swyg oor die rol van die Heilige Gees by die uitleg van die Skrif. Stuhlmacher meen dat sy Hermeneutiek van Instemming 'n brug slaan terug na die Reformasie en Calvyn se standpunt: "Das exegetischhistorische Bemuhen um die Erhellung des Wortsinnes der Heiligen Schrift hat gegenuber der Wirkung des Wortes als Instrument des Geistes dienende Funktion" (1975:73).

Stuhlmacher se Skrifbeskouing verskil grondliggend van die basiese uitgangspunt van die Histories-kritiese Metode. Hy wil die Skrif met vertroue benader (1975:71) terwyl die Histories-kritiese Metode begin met sistematiese twyfel $(1975: 83)$. Sommige wil hierdie twyfelstandpunt terugvoer na Descartes se filosofie. Descartes sê egter dat openbaring met Goddelike gesag daaraan verbonde, sonder twyfel aanvaar moet word (1965: 198). Harrisville (in Stuhlmacher. 1977:8) verwerp ook die bevinding dat hierdie twyfelstandpunt van Descartes af kom. Descartes se metodiese twyfel het op 'n ander vlak gelê.

Stuhlmacher aanvaar dus dat alle metodes gebruik kan word deur die teoloog in sy Skrifondersoek. Maar daar durf geen metodedwang wees nie en die metodes moet as 't ware deur die Heilige Gees gedirigeer word. In sy proefskrif het Tjaart van der Walt tot dieselfde gevolgtrekking gekom, naamlik dat die Skrif met 'n basiese vertroue benader moet word en dat daar ook geen skemadwang mag wees nie $(1962: 29)$

3.7.3 Fundamentalisme en Anti-Fundamentalisme

Aan die anderkant van die spektrum van Skrifbeskouings staan Funda- 
mentalisme, ook Skrifkrities omdat dit werk met vooroordele wat nie die Skriftoets kan deurstaan nie. Dit was al vir Dodd (1960:21) 'n probleem. Barr beskryf Fundamentalisme as 'n veelkantige probleem. Loader (1980:102) gee Barr se standpunt oor Fundamentalisme soos volg weer:

"1. Sterk klem op die onfeilbaarheid van die Bybel as Gods woord. Dit word met die inspirasieleer verbind en só verstaan dat enige 'fout' in die Bybel ontbreek.

2. 'n Vyandigheid teen die moderne kritiese studie van die Bybel.

3 . 'n Houding dat andersdenkendes afvallige Christene is, nie vertrou kan word nie en 'n gevaar inhou vir die ware geloof."

Du Plessis (1987:16) sẽ Fundamentalisme is die verabsolutering van Skrifonfeilbaarheid. Vorster (1980:124.125) sẽ dat die term "Skrifgesag" gebruik word sonder voldoende besinning.

Fundamentalisme opereer met na-Reformatoriese dogmatiese terme asof daarmee die laaste woord gesê is oor die aard en die gesag van die Skrif. Aan bogenoemde tekening kan nog toegevoeg word dat Fundamentalisme simplisties die woord van God en die Skrif as sinoniem aanvaar met eksegese wat nie die toets kan deurstaan nie. (Dis nou afgesien van die feit dat hulle Christus ook as die Woord aanvaar.)

In Suid-Afrika het die teologie in 'n groot mate ontwikkel tot wat enersyds as oorname van die Histories-kritiese Metode verstaan kan word, maar wat in sommige gevalle as Anti-Fundamentalisme bestempel moet word. So kom die volgende onwetenskaplikhede dan voor:

1. 'n Oordrewe instelling om foute in die Bybel uit te wys. Du Plessis (1987:11) doen dit byvoorbeeld met auton wat hy in Matt $21: 7$ laat slaan op tẻn onon kai ton pólon in plaas van op ta himatia.

2. 'n Onnatuurlike en onlogiese vrees vir Skrif met Skrif vergelyking. Cilliers Breytenbach vergelyk Paulus se gedagtes oor versoening met Griekse historiograwe, maar nie met byvoorbeeld Hebreers nie (1986a:257-264 en 1986b:696-704).

3. 'n Afkeer van harmoniëring (nie harmonisering nie - wat kunsmatig is). Die sogenaamde probleem van een of twee blindes in Matt $20: 29$ 34 , Mark $10: 46$ - 52 en Luk $18: 35$ - 43 kan met sinvolle harmoniering goed verstaan word.

4. 'n Neiging om doeblette sonder voldoende rede as botsend te sien. Du Plessis het probleme met die hemelvaartberig in die Evangelie van Lukas en in Handelinge, Luk $24: 50-53$ en Hand $1: 4-12$ (1987:10).

5. 'n Oormatige ywer om pseudonimiteit aan te toon. Dit geld ten opsigte van die Pastorale Briewe en in die jongste tyd van 2 Tessalonisense. Die hoe prioriteit wat hieraan gegee word vergelyk nie goed met byvoorbeeld die klein sakie wat Calvyn maak van die feit dat Petrus nie self 2 Petrus geskryf het nie. Op dié manier word die openbaring van God wat die kerk ten dienste is, gesubordineer aan minder belangrike ondersoeke.

6. Toespitsing op fragmente waar dit nie eerstens ten dienste van die kerk is nie, met gevolglike verwaarlosing van die geheel-konteks. Dink byvoorbeeld aan die praktyk met proefskrifte. 
7. 'n Hoogmoed (onbedoeld) ten opsigte van die eie navorsing en metode met geringskatting van die rol van die vroeë kerk en die gehalte van hulle arbeid, lewe en beslissinge. Daar word ook dikwels geen ag geslaan op die leiding van die Heilige Gees in die kerk nie.

Op die kerk, en dan veral op die teoloe rus die sware verantwoordelikheid om polarisering te vermy en om tot 'n verantwoordelike en gebalanseerde Skrifbeskouing te kom.

\section{SLOTOPMERKINGS}

Watter riglyne kom daar nou uit so 'n oorsig oor die historiese agtergrond ten opsigte van 'n Skrifbeskouing?

1. Die rol van die Heilige Gees in die totstandkoming van die Skrif (2 Tim $3: 16)$ en in die uitlegging van die Skrif (2 Pet $1: 20)$ moet steeds van primêre belang geag word.

2. Die beslissing oor die omvang van die Skrif bly ten diepste 'n geloofstandpunt. Dit kan aan toetsing onderhewig wees, maar dan met inagneming van die leiding van die Gees in die geskiedenis van die kerk, veral die vroee kerk.

3. Die Skrif moet bestudeer word met die doel dat die kerk God en die weg van ons verlossing beter sal ken.

4. Die Skrif en die woord van God moet nie geidentifiseer word nie, al is die Skrif ook woord van God.

5. Metodes is op sigself nie verwerplik nie, maar alle metodes moet onder die primêre leiding van die Heilige Gees met die woord staan.

\section{BRONNE WAARNA VERWYS IS}

Aalders, G. Ch 1952. Oud-Testamentische Canoniek. Kampen. Kok

1956. S v Apocriefen. ('hristelijke Encyclopedie 1. 257 - 260. Kampen: Kok

___ 1956a. S v Astruc Christelijke Encyclopedie 1. 359 . Kampen Kok

Barr. J 1983. Holy Scripture, Oxford: Clarendon Press.

1985. In Teventlow, H G. The . Iuthority of the Bible and the rise of the modern world.

Philadelphia: Fortress Press

Berkouwer, G. C. 1966 . De Heilige Schrift 1. Kampen: Kok

Breytenbach, C. 1986. Tradisie-historiese probleme rondom 'versoening' by Paulus. HTS 42, $257-264$.

1986a. Probleme rondom die interpretasie van die 'versoeningsuitsprake' by Paulus.

HTS $42.696-704$

Calvyn Institusie.

Childs. B. S. 1985. Old Testament Theology in a (anonical context. London: SCM Press

Descartes 1965. A discourse on method. Meditations and principles. Tr by J. Veitch London: Dent

Dodd, C H. 1960. The Authority of the Bible. London: Collins

Du Plessis. P. J. 1987. Fundamentalisme: ja of nee? Scriptura 20. 1 - 32.

Farmer. W. R. 1980. In Stoldt. H-H History and criticism of the Marcan Hypothesis. Tr by

D. L. Niewyk. Edinburgh: T and T. Clark

Feenstra, Y. 1961. s v Schriftkritiek. (hristelijke Encyclopedie V1, 117 - 119. Kampen: Kok

Fryer, N. S. L. 1987. The Historical-Critical Method Y'es or No" Scriptura 20, $41-70$

Harrisville. R. A. 1977. In Stuhlmacher. P. Historical (riticism and Theological Interpretation of Scripture. Philadelphia: Fortress Press

Koole, J. L. 1955. Het probleem van de canonisatie van het O.T. Kampen. Kok.

Kummel. W. G. 1978' The New Testament. The history of the investigation of its problems. Tr by S. McLean Gilmour and H. C. Kee London: SCM Press 


\section{6 - In die Skriflig}

Loader. J. A. 1980. Ortodokse fundamentalisme en die gebruik van die Ou Testament in Suid-Afrika. HTS 35 ( 1 en 2), 101 - 118.

1984. Opening van die akademiese jaar. ThEv XVII (2), 2 - 4.

Logan, S. T. 1987. The origins of modern attacks on biblical authority. WThJ XILIX (1), $119-142$

Linnemann, Eta s j Anmerkungen zum Studium der historisch-kritischen Theologie. LeefLoda: Christus fur dich.

Maier, G. 1978². Das Ende der historisch-kritischen Methode. Wuppertal: Theologischer Verlag Rolf Brockhaus.

Reventlow. H. G. 1985. The authority of the Bible and the rise of the modern world. Tr by J. Bowden. Philadelphia: Fortress Press.

Ridderbos. H. 1955. Heilsgeschiedenis en Heilige Schrift. Kampen: Kok.

Sanders, E. P. 1981'. Paul and Palestinian Judaism. A comparison of Religion. London: SCM Press.

1987. Jesus and Judaism. London: SCM Press.

Stoldt. H-H 1980. History and criticism of the Marcan Hypothesis. Tr by D. L. Niewyk. Edinburgh: T. and T. Clark.

Stuhlmacher. P. 1975. Schriftauslegung auf dem Wege zur biblischen Theologie. Gottingen Vandenhoeck \& Ruprecht. 1977. Historical Criticism and Theological Interpretation of Scripture. Tr by R. A Harrisville. Philadelphia: Fortress Press.

1979. Vom Verstehen des Neuen Testaments. Eine Hermeneutik. Gottingen: Vandenhoeck \& Ruprecht

Terlaak Poot, L. D. 1961. s v Toland. Christelijke Encyclopedie VI, Kampen: Kok.

Thiessen, H. C. 1943. Introduction to the New Testament. Grand Rapids: Eerdmans

Van Aarde, A. G. 1987. Die "kanon" agter die kanon: Die ontwikkeling van die kanonbegrip in die Nuwe Testament. Die Hervormer, 82 (4), 16

Van der Walt, T. 1962. Die koninkryk van God - naby!: eksegetiese verkennings van die toekomsperspektief van Jesus Christus volgens die getuienis van die Sinoptiese Evangelies. Kampen: Kok.

Van Unnik, W. C. 1956. s v Bauer. Christelijke Encyclopedie I. 485.486.

Van Wyk, J. H. 1987. Ongepubliseerd. Die Woord is waardevol. 'n Dogmatiese studie oor die reformatoriese Skrifbeskouing.

Vorster. W. S. 1980. 'Moderne eksegese' van die Nuwe Testament - 'n ondermyning van Skrifgesag? HTS 35 ( 1 en 2) $119 \cdot 130$ 